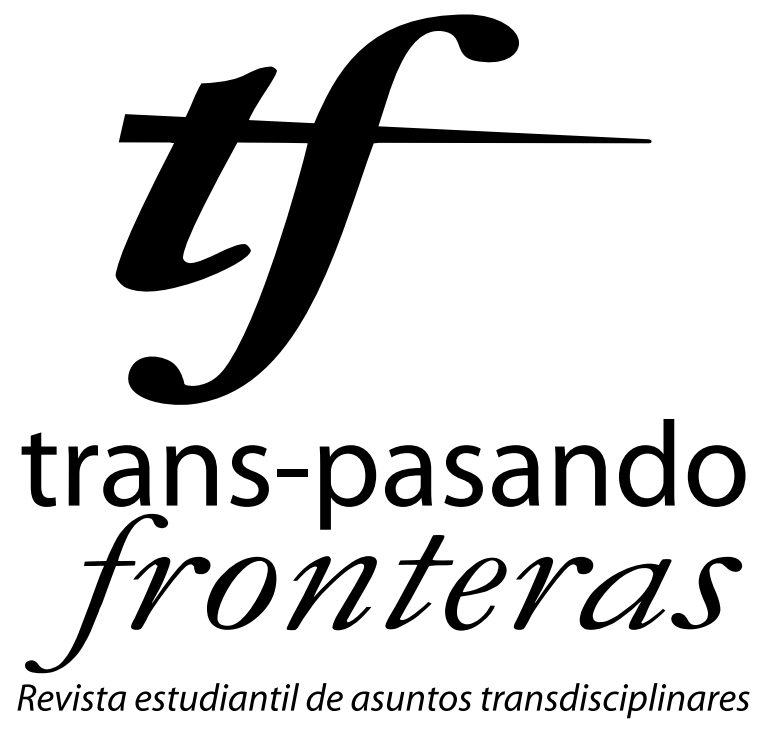

Una publicación de

Estudios

Interdisciplinarios

Jurídicos, Sociales

000 y Humanistas

ICESS

FACULTAD DE

DERECHO Y CIENCIAS

SOCIALES

然 UNIVERSIDAD 


\title{
Charlando sobre el ánimo de lucro en instituciones de educación superior y las movilizaciones estudiantiles en Chile y Colombia
}

\author{
Entrevista a Milton Vidal y Carlos Liévano
}

\author{
Por Adolfo A. Abadía \\ Estudiante de Ciencia Política, director de Estudiantes de Doxa y \\ editor ejecutivo de la revista Trans-pasando Fronteras \\ (adolfoabadia@yahoo.es)
}

La entrevista fue realizada el día jueves 3 de noviembre de 2011 en la Universidad Icesi en el marco del X Congreso Nacional de Sociología que se realizó en la ciudad de Cali entre el 2 y el 4 de noviembre de 2011.

Ese día contamos con la presencia del profesor Milton Vidal quien es el director de la Escuela de Sociología de la Universidad Academia de Humanismo Cristiano de Santiago de Chile. Además de ser Licenciado en Sociología obtuvo un postítulo en Estudios políticos europeos en la Universidad de Heidelberg y es $\mathrm{PhD}$.(c) en Ciencias sociales por la Universidad de Nijmegen, Holanda.

En la actualidad es presidente de la Red de Sociología de las Universidades chilenas (SOCIORED) e investigador del Grupo de Trabajo Políticas Educativas y Desigualdad en América Latina y El Caribe de CLACSO. Sus ámbitos de interés comprenden temas como la sociología de las políticas públicas y de la educación superior. 
"Este no es un problema de los otros, es decir de los estudiantes que van a ese tipo de universidades [privadas] sino que es un problema de todos, de toda la sociedad que paga impuestos y tributos para que sean garantizados los derechos como lo es la educación”"

Por su parte, Carlos Liévano ha participado en las diferentes facetas del movimiento estudiantil en Colombia, específicamente, desde la ciudad de Cali. En el 2010 hizo parte activa de los Encuentros Nacionales Estudiantiles Universitarios (ENEU) y contribuyó a la fundación de la Mesa Amplia Nacional Estudiantil (MANE) en el 2011, la cual ese mismo año logró derrocar el proceso de reforma de la Ley 30 sobre la educación superior.

Lideró la construcción de la Mesa
Amplia Estudiantil de Universidades Privadas (MALUP) de Cali y la Mesa Local Amplia Estudiantil de la Universidad Icesi. Paralelamente fue elegido por los estudiantes por el periodo de 2012-2013 como representante al Consejo académico de la Universidad Icesi.

Esta entrevista se presentó como una oportunidad para contrastar los trasfondos de las movilizaciones estudiantiles en Chile y en Colombia, en un momento muy particular. Estamos presenciando 
el nuevo despertar de las expresiones políticas estudiantiles, las cuales han emulado e incorporado nuevos repertorios para transmitir pacíficamente una situación de descontento generalizada.

Adolfo A. Abadía (AAA): ¿Cuál creen ustedes que han sido los motivos que esconden los gobiernos colombiano y chileno para hacer de la educación un negocio?

Milton Vidal (MV): En el caso chileno nos encontramos en un proceso de reforma legal y jurídica, al igual que en el caso de Colombia. La situación que tenemos consiste en una movilización muy importante, básicamente de estudiantes y de universidades paralizadas, lo que ha causado una postergación de semestres muy significativa.

Las demandas que ha planteado el movimiento chileno es una reforma al sistema actual de financiamiento de las universidades, con un aporte a las universidades del Estado que no superan un $20 \%$ de recursos. Otro punto fundamental es la democratización interna, es decir la generación de autoridades rectoras, directivos, entre otros, que permitan la participación de la comunidad estudiantil en procesos de toma de decisiones vinculantes.
Un tercer elemento es la situación con los estudiantes. La mayor parte de los estudiantes chilenos de educación superior están endeudados, en su mayoría con la banca privada donde las tasas de interés son diferentes a las tasas que cobra el Estado en los créditos que da para la educación. Lo que ha hecho el Estado hasta ahora es reaccionar a las demandas de los estudiantes sin atacar el problema de fondo como tal.

Carlos Liévano (CL): En el caso colombiano existe gran coincidencia en relación al último punto mencionado por el profesor Vidal. Colombia ha sostenido un modelo educativo durante aproximadamente 20 años. La reforma que se está planteando es sobre la Ley 30 de 1992 que busca desmontar la educación como derecho fundamental y entregarla a las lógicas de mercado, donde lo que importa es generar ganancias aún significando eso un detrimento en la calidad de la educación misma. Además de lo anterior, esta reforma generaría un vacío de recursos para las universidades públicas acarreando una reducción de la cobertura a razón de que los recursos serán cada vez menores.

Lo que ha venido sucediendo es que 
por falta de recursos económicos y por el incremento del Índice de precios al consumidor (IPC), las universidades públicas han tenido que empezar un proceso de autofinanciamiento. Una consecuencia de esto es la alza de las matrículas. Como reacción a esta situación, el Estado ha continuado limitando al máximo los recursos que recibirían las universidades públicas, a propósito de aumentar la cobertura, y ha comenzado a otorgar créditos a las familias para financiar el acceso de sus hijas e hijos a la educación superior, ocasionando una crisis económica en ciertos sectores sociales.

Mucho de los que observamos en las actuales movilizaciones ha sido propisiado, en gran parte, por esta nueva modalidad de crédito estatal.

AAA: Carlos, hace poco hubo una modificación a la reforma de la Ley 30 que deja por fuera de la negociación la creación de instituciones de educación superior con ánimo de lucro ${ }^{1}$. Significa esto el comienzo del fin de las movilizaciones estudiantiles.

\footnotetext{
1 Para mayor información consultar el artículo del 23 de agosto de 2011, “Ánimo de lucro no hará parte de la reforma a la ley 30 de educación superior" en Semana.com Consulta realizada desde http://www. semana.com/nacion/articulo/animo-lucro-no-hara-partereforma-ley-30-educacion-superior/245370-3
}

CL: Desde principios del año 2011, el Estado colombiano presentó un informe en el que incluía un elemento como el de “ánimo de lucro" en la educación. Por parte de la Universidad Icesi el rector Francisco Piedrahita escribió cuatro documentos rechazando esta postura, dejando en evidencia que las lógicas del mercado marcarían un nuevo destino para la educación. Sería el comienzo de la educación como un negocio de lucro al cual podrían llegar multinacionales a proveer un servicio con mayor cobertura pero sin ningún control de calidad.

A partir del conocimiento de este punto, la comunidad estudiantil empieza una serie de movilizaciones y logran que el gobierno retire de la reforma y abra un espacios de participación. Lo que los estudiantes estábamos planteando era quitar el ánimo de lucro, lo cual se ganó, sin embargo esto no modificaba el problema estructural de la educación respecto a las formas de financiación. Motivo por el cual la universidad pública ha perdido autonomía, calidad y financiación por parte del Estado.

AAA: Profesor Vidal, existen en Chile universidades con ánimo de lu- 
cro, o no existe esa figura allá en la educación superior.

MV: En Chile la Ley constitucional orgánica de 1990 fue aprobada un día antes de acabarse la dictadura. Tenía como objetivo regular la educación en general, pero básicamente era una ley de educación superior. La mayoría de los aspectos modificados correspondían a títulos universitarios y a la autonomía de las universidades. Esa Ley, por raro que parezca, no fijaba un ánimo de lucro para las instituciones educativas.

Naturalmente, las universidades creadas en los años 80 habían estado regidas por leyes distintas y no respondían a las dinámicas neoliberales de mercado ni al ánimo de lucro. Entonces, si uno miraba la realidad jurídica de los años 90 ninguna universidad podía responder al ánimo de lucro, ni las más antiguas públicas, privadas o católicas, ni las nuevas de segunda generación como las empresariales o de jesuitas, entre otras. El punto que quiero dejar en claro es, la Ley no autorizaba a ninguna universidad el ánimo de lucro. Esa sería la respuesta formal jurídica.

Probablemente, al día de hoy, todavía queden universidades que cumplan estrictamente con la Ley. Pero no son la mayoría y los estudiantes lo saben. Lo que ha ocurrido en Chile son los denominados resquicios, los cuales burlan la norma y buscan como fin el lucro.

En el caso de las universidades algo que se ha generado es una reacción social en el sentido que no se está cumpliendo la Ley, pero además las universidades se han estado lucrando del endeudamiento de la gente. Es así como se hace notoria la existencia de una clara diferencia entre un lucro generado por los aportes legales estatales y otro lucro, como de universidades que incrementan su presupuesto y se lo reparten sin la reinversión en las instituciones mismas.

Pero el asunto que agrava la situación es este otro tipo de lucro. Éste ocurre acosta del endeudamiento de familias de ingresos bajos que difieren la deuda a muchos años. Esto no solo afecta a los profesionales, sino principalmente a personas con títulos de técnicos que trabajan en condiciones precarias y que trabajan toda una vida para saldar cuentas. En este sentido, el avance social que debería verse en estas personas no está ocurriendo por que están siendo absorbidas por un sistema financiero.

Entonces, ¿qué es lo que está ocu- 
rriendo en Chile con las movilizaciones estudiantiles? Muchas universidades se han creado como empresas inmobiliarias donde compran terrenos y edificios para luego arrendarlos a instituciones educativas. De esta manera, las universidades le pagan a las inmobiliarias por utilizar las instalaciones de sus mismos ingresos. por tal motivo, se encuentran "universidades" con un amplio terreno y que manejan al interior la publicidad de sus programas, no obstante son universidades que han adquirido contratos de arriendos cuyos costos son asumidos por los estudiantes.

Este no es un problema de los estudiantes que van a ese tipo de universidades, sino que es un problema de todos, de toda la sociedad que paga impuestos $\mathrm{y}$ tributos para que sean garantizados los derechos como el de la educación. Lo quieran o no, este problema es societal e involucra no solo al Estado que debe garantizar la distribución de recursos sino a la sociedad como tal.

CL: Yo quisiera mencionar dos aspectos en cuanto al ánimo de lucro en Chile, y es que nosotros debemos aprender del caso chileno para revisar los procesos que están ocurriendo en Colombia.
Como bien menciona el profesor Vidal, el ánimo de lucro en Chile no está legalmente establecido pero las empresas se han buscado los mecanismos y las formas para lucrarse de los dineros del Estado y de los créditos de los estudiantes. $\mathrm{Y}$ esto es, de alguna forma, ánimo de lucro. Eso no está en la reforma que se tramita aquí en Colombia, pero es un aspecto que podría llegar a suceder y es pertinente conocer a fondo las dinámicas que se buscan con la reforma en cuanto a los métodos de financiación para la educación superior.

Por ejemplo, en Colombia ya hay una multinacional que compró la universidad en Bogotá llamada "Gran Politécnico Colombiano". Esto ya sirve de evidencia que, sin aún ser aprobada la reforma, existe ánimo de lucro. Por lo tanto puede suceder lo que pasa en Chile, donde empresas se valen de mecanismos formales, como el inmobiliario, para evadir la Ley, aumentar los costos de pago en la educación superior e ir en detrimento con la calidad. Esto sin desconocer que si se firma un TLC con EE.UU. se le brindaría garantías a multinacionales para que entren a competir en un mercado 
que debería ser proveído por el Estado como derecho fundamental.

AAA: Para finalizar considero importante resaltar los repertorios que las movilizaciones ciudadanas, en particular, las estudiantiles, han tomado, por ejemplo en el 2006 en Chile y en 2011 en Colombia. Celebro todo tipo de acción social pacífica y sobre todo aplaudo las formas creativas, como veo, en que éstas se han transformado. Pero antes que esto, podríamos analizar un poco ¿cómo se articulan las movilizaciones con las reformas?.

A mi parecer, podría decirse que la movilización queda siempre como último recurso para la expresión política ciudadana de demandas por derechos fundamentales, además de la educación, otros como de salud, vivienda, seguridad social, entre otros.

MV: Así como hay diferencias entre el derecho a la educación y el servicio que se ofrece, en Chile pasamos de una garantía del derecho a la educación a prestar un servicio del mismo. Por lo tanto, se amplió la libertad de acceso a la educación en tanto a que los jóvenes y sus familias tienen mayor oferta y pueden elegir donde estudiar. Situación que varía según nivel de ingreso o capacidad de endeudamiento. Ahora, considero que una de las respuestas del Estado debería ser la de proveer distintas alternativas y modalidades de financiamiento.

Los movimientos estudiantiles están representado el sentimiento social generalizado que busca reevaluar la cultura de derechos que tenemos en Chile, es decir, reflexionar ante la pregunta ¿somos portadores del derecho a la educación o definitivamente no lo somos? es también definir si es el Estado o la sociedad quien tiene que respetar este derecho, o si es el derecho mismo el que está siendo cuestionado, o si lo es solamente las formas de financiamiento.

Todo esto es lo que está en juego en estas movilizaciones. Déjenme pongo un pequeño ejemplo para ilustrar mejor la situación. Si una familia no tiene suficiente dinero o está rotundamente endeudada ¿qué pasa entonces con el derecho a educarse? todo esto sin ni siquiera hablar del ánimo de lucro.

Para culminar quiero dejar en claro que el punto más importante que deben compartir las movilizaciones, tanto en Chile como en Colombia, es el de dar a conocer lo que sucede y presentar alternativas viables no solo de interés 
para los estudiantes sino para nuestro futuro como sociedad.

Así, aunque el gobierno chileno responde de una manera muy derechista al mencionar que se "viene el caos", los estudiantes han sabido responder de una manera muy inteligente al incluir maneras significativas de movilización que incluye a las madres y padres de familia, a los profesores, rectores, niños de preescolar; han tratado de darle colorido a las movilizaciones, tanto así que hasta los partido políticos han acompañado estos procesos mostrando sus banderas. Pero la bandera de este movimiento es heterogénea representada por diversos sectores de la sociedad que buscan garantías de un derecho dentro de todo el sistema educativo.

No obstante, también se unen las demandas de grupos ambientalistas, de género que se sienten excluidos pero luchan por una reivindicación social y reconocimiento. Así vemos como por este motivo el movimiento social ha ganado más fuerza en la medida en que incluye a varios sectores sociales ganando el apoyo mediante la interlocución mutua.

CL: La movilización ha tenido históricamente grandes resultados $\mathrm{y}$ ha permitido grandes cambios en la socie- dad. Y Colombia no es la excepción. Las movilizaciones han permitido una integración mayor de distintos sectores estudiantiles en la Mesa Amplia de Negociación Estudiantil (MANE), la cual le está haciendo seguimiento y frente a la reforma de la Ley 30.

Cabe mencionar que conseguir lo que se ha logrado hasta ahora no ha sido fácil. Ha demandado todo un proceso de organización y de articulación de la mayoría de las agrupaciones estudiantiles colombianas. Pero fuimos conscientes que si se quería hacer frente a la mayoría legislativa de congresistas afín de la "unión" con el presidente, debíamos actuar de manera rápida e inteligente.

En este sentido, las movilizaciones fueron de una manera muy pacífica y en cierta manera lo que se pretendía era organizar algo así como un carnaval, al cual se vincularon madres y padres de familia, obreros, se abrazó a la policía como un gesto de amistad, se llevaron jornadas de "besatones" y "abrazatones", de marchas con antorchas por la noche, en general toda una nueva gama de repertorios pacíficos, completamente opuesto a los disturbios y actos vandálicos con los que seguramente el 
Estado colombiano estaba contando.

Lo importante de todo esto fue que se pudo dar a conocer al movimiento estudiantil como renovado y con una visión distinta de hacer protestas. Es así como se exige derogar la Ley en trámite desde el Ministerio de Educación y presentar una nueva que garantice la educación como derecho fundamental acorde a un modelo de país que busque bienestar para todos. 